\title{
Performance Evaluation of Multiple Helical Tubes as a ReCEIVER FOR SOlar Parabolic Trough Collector
}

\section{Swapnil N. Lotake*, M. M. Wagh}

\author{
Energy Technology, Department of Technology, Shivaji University, Kolhapur, INDIA
}

Email for Correspondence: lotakeswapnil@gmail.com

Manuscript Received: 05 December 2019

Revised: 15 March 2020

Accepted: 27 March 2020

Abstract

Solar parabolic trough collector consists of a parabolic reflector with a central receiver at a focal point through which heat transfer fluid is passed. Parabolic trough collector is used mostly in solar thermal power plants for generating electricity. This paper describes the experimental results of two straight tubes wrapped over each other to form a helically shaped receiver. The receiver was tested with aluminium material with and without black paint over it. Also, the helical tube receiver was tested with a glass cover over it, at two different mass flow rates and, with and without manual tracking. The tested instantaneous thermal efficiency ranges from $31.26 \%$ to $45.28 \%$ and the overall thermal efficiency ranges from $14.9 \%$ to $31.41 \%$ during the experimental period. The instantaneous thermal efficiency increased by an average of 1.32 times for unpainted receiver and 1.36 times for black painted receiver with the increase in mass flow rate. By tracking the parabolic collector according to sun's position, there is an average increase in instantaneous thermal efficiency by 1.1 times for unpainted receiver and 1.04 times for black painted receiver. The paper further reveals that the use of multiple helical tubes as a receiver for parabolic trough collector increases the overall efficiency of the collector in a substantial manner.

Key words

Multiple helical tubes, solar parabolic trough collector, receiver, solar thermal, solar energy, heat transfer

This article is is licensed under a Creative Commons Attribution-NonCommercial 4.0 International License.

Attribution-Non Commercial (CC BY-NC) license lets others remix, tweak, and build upon work non-commercially, and although the new works must also

acknowledge \& be non-commercial.

\section{INTRODUCTION}

Solar parabolic trough collector consists of solar collectors (mirrors or reflecting surfaces), heat receivers or receivers and support structure. The solar collectors of the parabolic trough are constructed and made by forming a sheet of reflective material into a parabolic shape that collects the incident sunlight and concentrates it onto a central receiver or receiver which is located at the focal point of the parabolic sheet. The collectors can be of different lengths and aperture depending on the application for which it is used. The collectors can be as long as 100 meters or more and the aperture can be 5 meters wide or more.

The receiver of the parabolic trough consists mainly of a receiver tube in which a fluid is made to flow. The receiver tube is generally a coated tube, with a selective coating that absorbs the solar irradiation, but emits very little infrared radiation. This helps to reduce heat loss. The fluid which is made to flow through the receiver is called as a Heat Transfer Fluid (HTF). This HTF collects the solar energy which is heat energy. This energy can then be utilized for different purposes.

\section{LITERATURE REVIEW}

Huang et al. (2015) carried out a numerical simulation on the inner tube of a receiver of a parabolic trough collector with and without helical fins, protrusions and dimples. In the study, the receiver tube of traditional LS-3 parabolic trough solar collector was adopted. The tube wall was made of stainless steel.

Suraj Gurav (2015) performed a parametric comparison of heat transfer in Helical and Straight Tube-In-Tube heat exchanger. The heat transfer coefficient in helical heat exchanger increased with flow rate and approached a 
maximum value at higher flow rates. It was observed that the heat transfer coefficient for helical tube-in-tube arrangement is approximately 10 to 20 times that of straight tube-in-tube arrangement. For the same surface area, it was observed that the heat energy absorbed by helical tube is more than that of a straight copper tube.

Hoste and Schuknecht (2014) of SkyFuel Inc. tested a SkyFuel developed and built parabolic trough collector Sky Trough ${ }^{\circledR}$ DSP (Dispatchable Solar Power). A receiver of $80 \mathrm{~mm}$ and $90 \mathrm{~mm}$ in diameter was tested. Overall results indicated a $76 \%$ optical efficiency, and thermal efficiencies ranging from $65 \%$ to $75 \%$, conditional to the operating temperature of the heat transfer fluid (HTF).

Kajavali et al. (2014) performed an investigation of heat transfer enhancement in a parabolic trough collector with a modified absorber. Experiments are conducted on a single tube absorber and a newly designed modified absorber with an absorber plate and a linear array of water tubes. The day average efficiency of the proposed modified absorber system was found to be $42.1 \%$ which is higher than the conventional single tube absorber systems.

Zhu et al. (2014) experimentally studied heat transfer enhancement by Dean vortices in spiral tubes. Experiments were carried out under constant wall temperature condition with one straight copper tube and 7 kinds of spiral copper tubes. The results showed that the Nusselt number of the flow in spiral tubes increases with Reynolds number, viscosity and curvature ratio, but changes anomalously with the torsion.

Ranjbar and Seyyedvalilu (2014) numerically investigated the effect of geometrical parameters on heat transfer coefficient in helical double tube exchangers. The results indicate that heat transfer augments by increasing the inner Dean number, inner tube diameter, curvature ratio, and by the reduction of the pitch of the heat exchanger coil.

Ghadirijafarbeigloo et al. (2014) carried out a 3-D numerical investigation on a laboratory type receiver tube of a parabolic trough collector. In this study, enhancement of convection coefficient in the receiver tube by equipping it with a new perforated louvered twisted tape (LTT) was studied numerically. For numerical simulations, three different twist ratios were used.

Naveenraj et al. (2013) developed a 3D numerical model of a porous disc receiver for parabolic trough collector to enhance heat transfer. The porous disc receiver is made of silicon carbide ( $\mathrm{SiC}$ ) and enclosed by a glass envelope to reduce the heat loss to the surroundings. The internal area of the receiver is increased by incorporating porous discs inside the receiver. The introduction of the porous disc in the receiver improves the heat transfer characteristics of the receiver with a pressure drop as a penalty.

Islam et al. (2012) performed a three-dimensional simulation on a parabolic trough collector receiver. The receiver considered was a tube $8 \mathrm{~m}$ long and had $70 \mathrm{~mm}$ outside diameter and $66 \mathrm{~mm}$ inside diameter. In order to increase the flow velocity, a $50.8 \mathrm{~mm}$ diameter closed-end plug tube was inserted inside the receiver tube. The receiver was covered with a glass envelope with $109 \mathrm{~mm}$ inner diameter and $115 \mathrm{~mm}$ outer diameter. Between the receiver and the glass envelope, the evacuated region was considered.

Cheng et al. (2012) numerically studied heat transfer enhancement by unilateral longitudinal vortex generators inside parabolic trough solar receivers. The longitudinal vortex generators were only located on the side of the absorber tube with concentrated solar radiation. The effects of Reynolds number, heat transfer fluid (HTF) inlet temperature, and incident solar radiation and LVG geometric parameters were further examined.

From the above literature, it has been observed that there is a significant amount of change in the performance of a solar parabolic trough because of changes made in the receiver. Till now, the maximum thermal efficiency achieved in the solar parabolic trough is $76 \%$. Various modifications in the receiver lead to changes in the heat transfer coefficient between heat transfer fluid and receiver.

So, still, there is a scope of improvement in the thermal efficiency of the parabolic trough. Use of helical tube in heat exchangers has led to an increase in efficiency in the heat exchangers. The receiver of the trough is also a type of heat exchanger. Therefore, the use of helical tubes may lead to an increase in the heat transfer when used as a receiver for solar parabolic trough collector.

\section{EXPERIMENTATION}

A schematic sketch of the test setup is shown in Figure 1. It consists of a solar collector, storage tank of 100-L capacity and control valve at the water tank used to regulate the flow rate through the circuit. The necessary instruments are attached to the apparatus and then measurements were taken.

The following data collection instruments were used.

1. Solar radiation: solar meter 
2. Wind Velocity: digital anemometer

3. Temperature measurements: set of thermocouple with digital displays and temperature gun to measure surface temperature

4. Pressure difference: digital manometer is used to measure pressure difference between two points

a - Flow control valve

b - Inlet temperature sensor

c - Outlet temperature sensor

$\mathrm{d}$ - Solar radiation meter

e - Digital Differential Manometer

f - Anemometer

g - Storage tank

$\mathrm{C}$

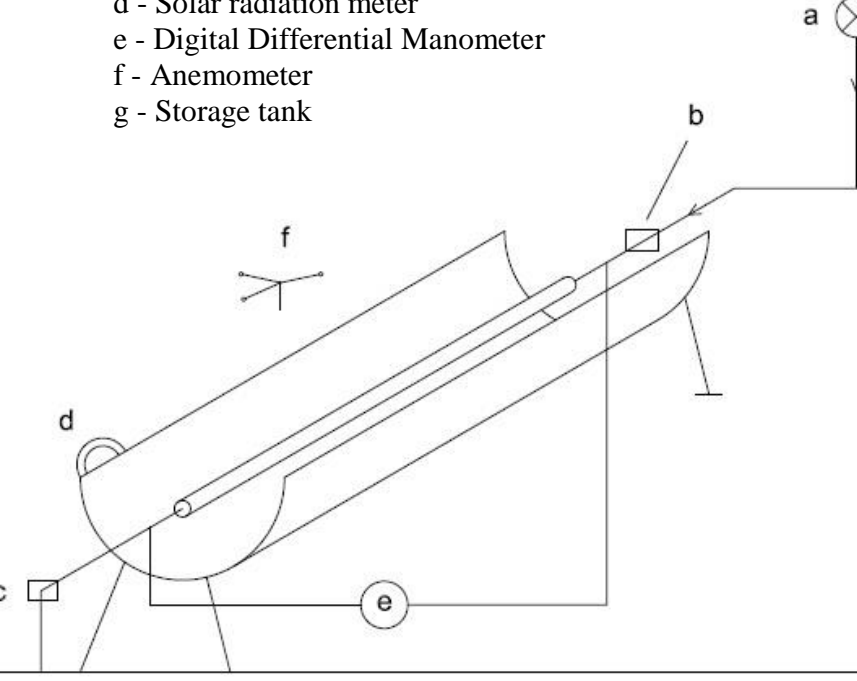

a

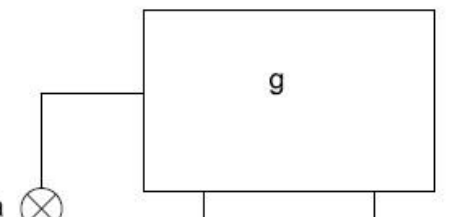

Figure 1: Schematic Diagram of the setup

\section{Multiple Helical Tubes as a Receiver}

The multiple helical tube receiver consists of wrapping of a number of straight tubes over each other. For the current work, two tubes of same dimensions were used. The two tubes were wrapped over each other to form a helically shaped receiver. The design of the multiple helical tube receiver was carried considering the solar parabolic trough collector and heat exchanger design. The assembly of the multiple helical tube receiver is shown in figure 2 . The dimensions of the helical tubes are given in table I. As the tubes are in contact with each other, the coil diameter becomes almost equal to the outer diameter of a single tube.

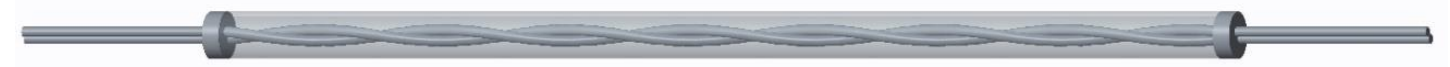

Figure 2: Helical Tube Receiver Assembly

\section{TESTING}

The experiment was carried out with water as a heat transfer fluid. The working of all the instruments was checked whether they are proper or not including the tracking of the collector. Proper care was taken to see that there is no leakage of water during the experimentation. The tank was located at a certain height above the collector so as to allow the natural flow of the water. An attachment was made after the flow control valve to allow two separate flows of water to both the helical tubes.

An equal number of readings were taken before, after and at the solar noon time of the location. Minimum four readings were required to be taken before and after the solar noon time. The periods should be chosen so that the measurement data points are at times symmetrical to solar noon. The experiment was carried out from 1151 hours to 1315 hours. The experiment was carried out with and without black paint on the receiver as well as for three different mass flow rates.

During the experimentation, the collector was oriented with its focal axis pointed in the East-West direction. Manual tracking and without tracking was also carried out for the above receiver input parameters of paint and mass flow rates. The trough was rotated about E-W axis and manually adjusted so that the solar radiation is perpendicular to the reflector. 
Table 1: Parameters and dimensions of parabolic trough collector used in the experimentation

\begin{tabular}{|l|c|}
\hline \multicolumn{1}{|c|}{ Parameter } & Dimension \\
\hline Aperture of the collector & $1.1 \mathrm{~m}$ \\
\hline Inner diameter of single helical tube & $0.011 \mathrm{~m}$ \\
\hline Outer diameter of single helical tube & $0.012 \mathrm{~m}$ \\
\hline Inner diameter of glass tube & $0.048 \mathrm{~m}$ \\
\hline Outer diameter of glass tube & $0.05 \mathrm{~m}$ \\
\hline Length of helical tube receiver & $0.88 \mathrm{~m}$ \\
\hline Concentration ratio & 13.69 \\
\hline Outer diameter of single helical tube & $12.5 \mathrm{~mm}$ \\
\hline Inner diameter of single helical tube & $11 \mathrm{~mm}$ \\
\hline Number of turns & 2 \\
\hline Coil diameter & $12.5 \mathrm{~mm}$ \\
\hline
\end{tabular}

\section{Thermal Performance of the Parabolic Trough Collector}

\section{Thermal Performance calculations}

The useful heat gain to the heat transfer fluid is calculated experimentally as follows,

$\mathrm{q}_{\mathrm{u}}=\dot{\mathrm{m}} \mathrm{C}_{\mathrm{p}}\left(\mathrm{T}_{\text {out }}-\mathrm{T}_{\mathrm{in}}\right)(\mathrm{W})$

where, $\dot{\mathrm{m}}=$ mass flow rate of the heat transfer fluid $(\mathrm{kg} / \mathrm{s})$

$\mathrm{C}_{\mathrm{p}}=$ specific heat of the heat transfer fluid $(\mathrm{J} / \mathrm{kg}-\mathrm{K})$

$\Delta \mathrm{T}=$ Temperture difference of the fluid $(\mathrm{K})$

$=$ Outlet fluid temperature - Inlet fluid temperature

The useful heat gain to the heat transfer fluid is calculated theoretically as follows,

$\mathrm{Q}_{\mathrm{u} \text {, theo }}=\mathrm{F}_{\mathrm{r}}\left(\mathrm{w}-\mathrm{d}_{\mathrm{r}}\right) \mathrm{L}\left[\mathrm{S}-\frac{\mathrm{U}_{\mathrm{l}}}{\mathrm{CR}}\left(\mathrm{T}_{\mathrm{in}}-\mathrm{T}_{\mathrm{a}}\right)\right]$

where, $\mathrm{Q}_{\mathrm{u}, \text { theo }}=$ theoretical useful heat $(\mathrm{W})$

$\mathrm{F}_{\mathrm{r}}=$ heat removal factor

$\mathrm{W}=$ aperture of the reflector $(\mathrm{m})$

$\mathrm{d}_{\mathrm{r}}=$ outer diameter of the receiver $(\mathrm{m})$

$\mathrm{L}=$ length of the receiver $(\mathrm{m})$

$\mathrm{S}=$ incident solar radiation $\left(\mathrm{W} / \mathrm{m}^{2}\right)$

$\mathrm{U}_{1}=$ overall heat loss coefficient $\left(\mathrm{W} / \mathrm{m}^{2}-\mathrm{K}\right)$

$\mathrm{CR}=$ concentration ratio

$\mathrm{T}_{\mathrm{i}}=$ inlet temperature of the heat transfer fluid $(\mathrm{K})$

$\mathrm{T}_{\mathrm{a}}=$ ambient temperature $(\mathrm{K})$

The experimental and theoretical instantaneous thermal efficiency is calculated as,

$\eta=\frac{\mathrm{q}_{\mathrm{u}}}{\mathrm{I}_{\mathrm{c}}(\mathrm{w} \times \mathrm{l})}$

$\eta_{\text {theo }}=\frac{\mathrm{Q}_{\mathrm{u}, \text { theo }}}{\left(\mathrm{I}_{\mathrm{b}} \mathrm{r}_{\mathrm{b}}+\mathrm{I}_{\mathrm{d}} \mathrm{r}_{\mathrm{d}}\right)(\mathrm{w} \times \mathrm{l})}$

where, $\mathrm{Q}_{\mathrm{u} \text {,theo }}=$ theoretical useful heat $(\mathrm{W})$

$\mathrm{Ib}=$ incident beam radiation $\left(\mathrm{W} / \mathrm{m}^{2}\right)$

$\mathrm{r} b=$ geometrical or tilt factor for beam solar radiation

$\mathrm{I}_{\mathrm{d}}=$ incident diffused radiation $\left(\mathrm{W} / \mathrm{m}^{2}\right)$

$r_{d}=$ geometrical or tilt factor for diffused solar radiation

The experimental overall thermal efficiency is calculated as

$\eta_{c}=\frac{\int_{0}^{t} q_{u} d t}{\int_{0}^{t} I_{c} A_{c} d t}$

where, $\mathrm{q}_{\mathrm{u}}=$ useful heat gain $(\mathrm{W})$

$\mathrm{I}_{\mathrm{c}}=$ incident solar radiation $\left(\mathrm{W} / \mathrm{m}^{2}\right)$

$\mathrm{A}_{\mathrm{c}}=$ collector area $\left(\mathrm{m}^{2}\right)$ 


\section{Overall Heat Loss Coefficient}

The overall heat loss coefficient is calculated by considering convection and re-radiation losses occurring in the receiver and glass tube. Heat loss rate per unit length is calculated as below,

$$
\begin{aligned}
& \frac{\mathrm{q}_{1}}{\mathrm{~L}}=\mathrm{h}_{\mathrm{r}, \mathrm{g}}\left(\mathrm{T}_{\mathrm{r}}-\mathrm{T}_{\mathrm{g}}\right) \pi \mathrm{D}_{\mathrm{o}}+\frac{\sigma \pi \mathrm{D}_{\mathrm{o}}\left(\mathrm{T}_{\mathrm{r}}^{4}-\mathrm{T}_{\mathrm{g}}^{4}\right)}{\left(\frac{\mathrm{D}_{\mathrm{o}}}{\frac{1}{\varepsilon_{\mathrm{r}}}+\mathrm{D}_{\mathrm{gi}}\left(\frac{1}{\varepsilon_{\mathrm{g}}} 1\right)}\right)} \\
& \frac{\mathrm{q}_{\mathrm{l}}}{\mathrm{L}}=\mathrm{h}_{\mathrm{w}}\left(\mathrm{T}_{\mathrm{g}}-\mathrm{T}_{\mathrm{a}}\right) \pi \mathrm{D}_{\mathrm{go}}+\sigma \pi \mathrm{D}_{\mathrm{go}} \varepsilon_{\mathrm{g}}\left(\mathrm{T}_{\mathrm{r}}^{4}-\mathrm{T}_{\mathrm{sky}}^{4}\right) \\
& \mathrm{U}_{\mathrm{l}}=\frac{\mathrm{q}_{1} / \mathrm{L}}{\mathrm{A} \times\left(\mathrm{T}_{\mathrm{r}}-\mathrm{T}_{\mathrm{a}}\right)}
\end{aligned}
$$

Where, $\mathrm{q}_{1} / \mathrm{L}=$ heat loss from the receiver per unit length $(\mathrm{W} / \mathrm{m})$

$h_{\mathrm{pc}}=$ convective heat transfer coefficient between annular gas and receiver $\left(\mathrm{W} / \mathrm{m}^{2}-\mathrm{K}\right)$

$\mathrm{T}_{\mathrm{r}}=$ receiver surface temperature $(\mathrm{K})$

$\mathrm{T}_{\mathrm{g}}=$ inner surface glass tube temperature $(\mathrm{K})$

$\mathrm{D}_{\mathrm{o}}=$ outer diameter of receiver $(\mathrm{m})$

$\varepsilon_{\mathrm{r}}=$ emissivity of receiver

$\varepsilon_{\mathrm{g}}=$ emissivity of glass

$\mathrm{D}_{\mathrm{g}, \mathrm{i}}=$ inner diameter of glass tube $(\mathrm{m})$

$\mathrm{D}_{\mathrm{g}, \mathrm{o}}=$ outer diameter of glass tube $(\mathrm{m})$

$\mathrm{h}_{\mathrm{w}}=$ convective heat transfer coefficient between glass tube and wind $\left(\mathrm{W} / \mathrm{m}^{2}-\mathrm{K}\right)$

$\mathrm{T}_{\mathrm{a}}=$ ambient temperature $(\mathrm{K})$

$\mathrm{T}_{\text {sky }}=$ sky temperature $(\mathrm{K})$

\section{Heat transfer coefficient between multiple helical tube receiver and glass tube}

The convective heat transfer coefficient between the helical tube receiver and glass tube is calculated as follows,

$\frac{\mathrm{k}_{\text {eff }}}{\mathrm{k}}=0.317\left(\mathrm{Ra}^{*}\right)^{0.25}$

$\left(\mathrm{Ra}^{*}\right)^{0.25}=\frac{\ln \left(\frac{\mathrm{D}_{\mathrm{gi}}}{\mathrm{D}_{\mathrm{o}}}\right)}{\mathrm{b}^{0.75}\left(\frac{1}{\mathrm{D}_{\mathrm{o}}^{0.6}}+\frac{1}{\mathrm{D}_{\mathrm{gi}}^{0.6}}\right)} \times \mathrm{Ra}^{0.25}$

$h_{r, g}=\frac{2 k_{\text {eff }}}{D_{0} \times \ln \left(\frac{D_{g i}}{D_{\mathrm{o}}}\right)}$

where, $k_{\text {eff }}=$ effective thermal conductivity of annulus air $(\mathrm{W} / \mathrm{m}-\mathrm{K})$

$\mathrm{k}=$ thermal conductivity of annulus air $(\mathrm{W} / \mathrm{m}-\mathrm{K})$

$\mathrm{Ra}=$ Rayleigh's number

$\mathrm{D}_{\mathrm{g}, \mathrm{i}}=$ glass tube inner diameter $(\mathrm{m})$

$\mathrm{D}_{\mathrm{o}}=$ receiver outer diameter $(\mathrm{m})$

$h_{r, g}=$ convective heat transfer coefficient between the glass tube and receiver $\left(\mathrm{W} / \mathrm{m}^{2}-\mathrm{K}\right)$

Heat transfer coefficient between multiple helical tube receiver and heat transfer fluid

Similar to Reynold's number for flow in pipes, Dean Number is used to characterize the flow in a helical pipe.

$\operatorname{De}=\operatorname{Re}\left(\frac{r_{i}}{R_{\text {coil }}}\right)^{0.5}$

In case of laminar flow, for $20<\mathrm{De}<2000$ and $0.7<\operatorname{Pr}<175$ and $0.0267<\mathrm{d} / \mathrm{D}<0.0884$, Nusselt number is given by Muñozet and Abánades (2011).

$\mathrm{Nu}=\left(2.153+0.318 \mathrm{De}^{0.643}\right) \operatorname{Pr}^{0.177}$

If the flow inside the tube is in the turbulent regime and the ranges of Dean number and Prandtl number are 2000 to 12000 and 1.0 to 3.5 respectively, then the Nusselt number inside the helical tube can be given by Jayakumara et al. (2011).

$\mathrm{Nu}=0.025 \mathrm{De}^{0.9112} \operatorname{Pr}^{0.4}$ 


\section{RESULTS AND Discussions}

The maximum and overall thermal efficiency for different cases obtained from the experimentation are shown in table 1 and table 2 respectively.

Figures 3 and 4 explain the variation of instantaneous thermal efficiency with respect to time for different mass flow rates and with or without manual tracking for unpainted and black painted receiver respectively. The instantaneous thermal efficiency increases with increase in the mass flow rate. Also, the instantaneous thermal efficiency increases when the solar parabolic trough collector is manually tracked according to the sun's position while keeping the mass flow rate constant. From figures 3 and 4, it can be stated that there is an increase in the thermal efficiency of the receiver when it is painted black as compared to the unpainted receiver.

Figure 5 shows the variation of heat loss coefficient between helical tube receiver and glass tube. The heat loss coefficient of the receiver is not always a constant but a function of receiver temperature and ambient conditions. The heat loss coefficient depends mainly on the wind velocity when the collector is tested in outdoor conditions. It can be found from the above graphs that the heat loss coefficient increases with increase in the wind velocity. From figure 5, it can be seen that the heat transfer coefficient is higher in the case of black painted receiver as compared to the unpainted receiver.

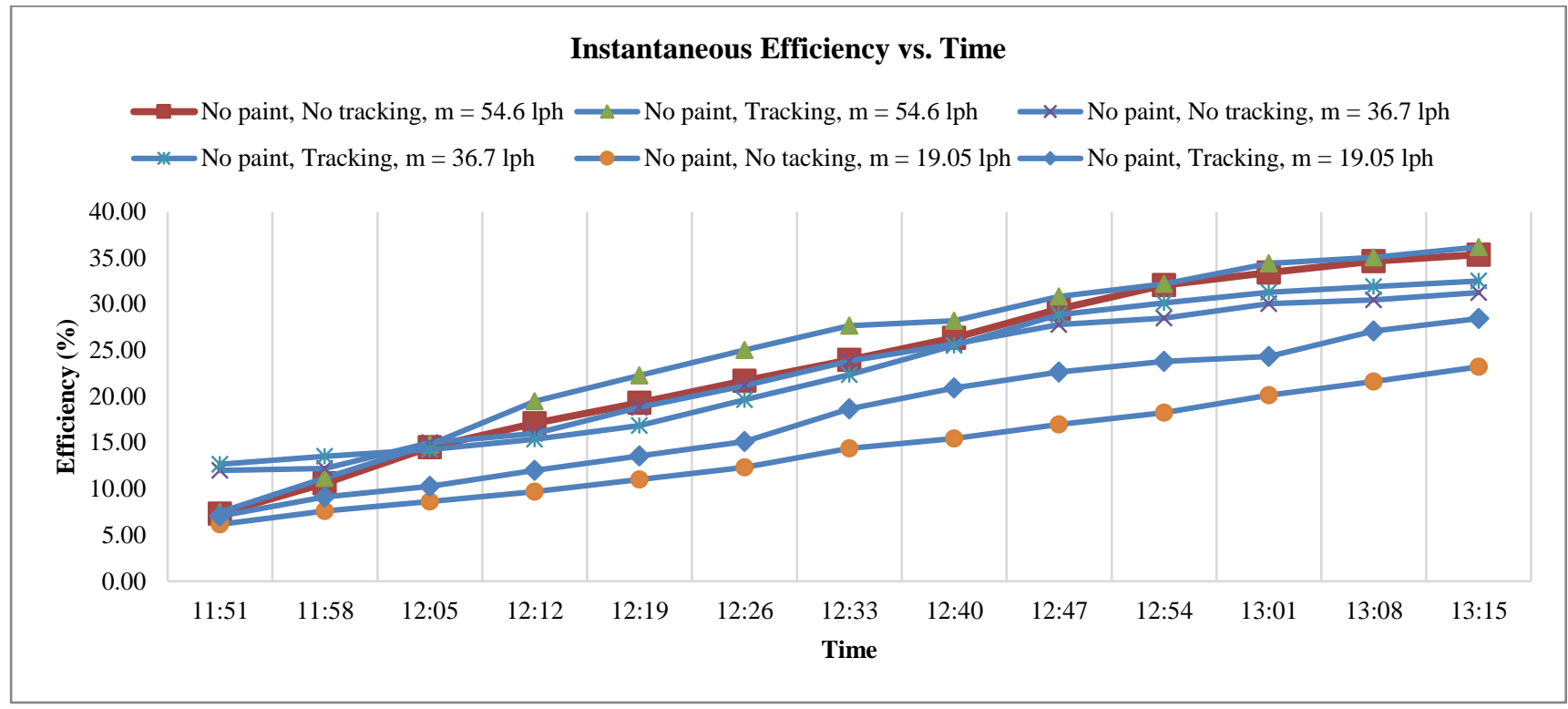

Figure 3: Instantaneous Efficiency vs. Time for unpainted receiver

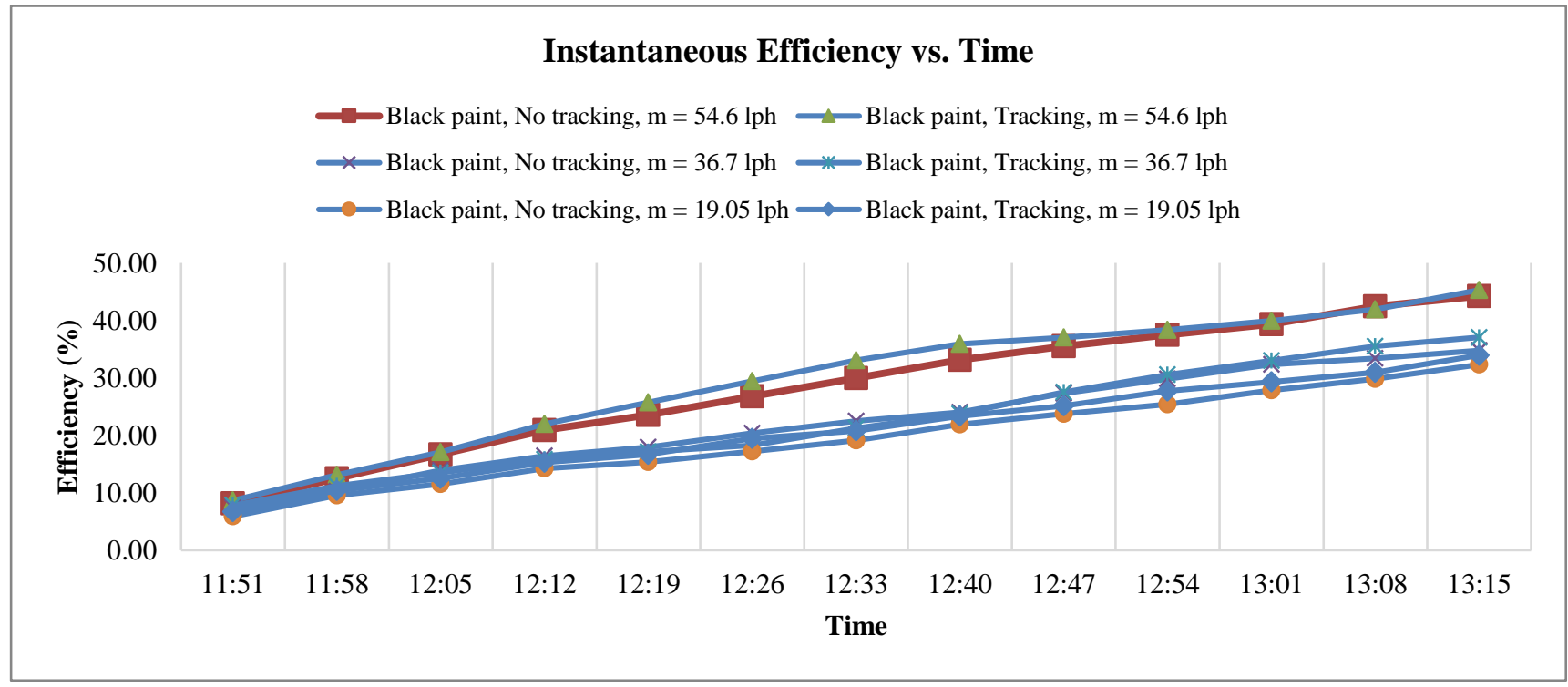

Figure 4: Instantaneous Efficiency vs. Time for black painted receiver 
Heat loss coefficient vs. Wind speed

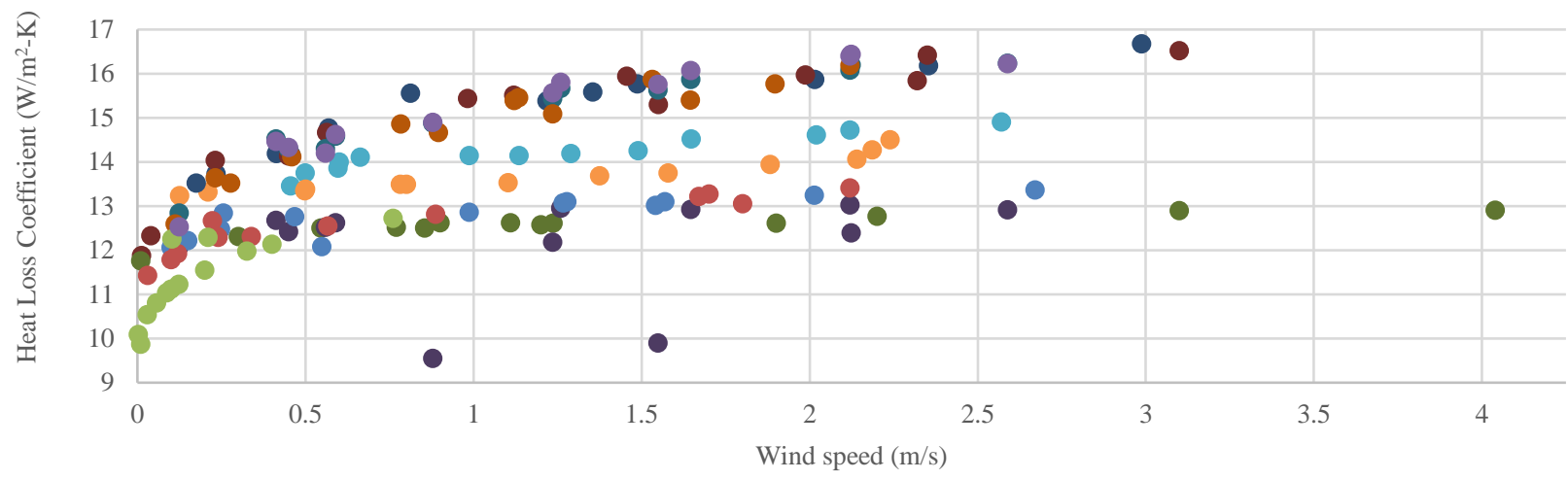

No paint, No tracking, $m=54.6 \mathrm{lph}$

- Black paint, no tracking, $\mathrm{m}=54.6 \mathrm{lph}$

- No paint, No tracking, $\mathrm{m}=36.7 \mathrm{lph}$

- Black paint, no tracking, $\mathrm{m}=36.7 \mathrm{lph}$

- No paint, No tracking, $\mathrm{m}=19.05 \mathrm{lph}$

- Black paint, no tracking, $\mathrm{m}=19.05 \mathrm{lph}$
No paint, Tracking, $\mathrm{m}=54.6 \mathrm{lph}$

- Black paint, Tracking, $\mathrm{m}=54.6 \mathrm{lph}$

- No paint, Tracking, $\mathrm{m}=36.7 \mathrm{lph}$

- Black paint, Tracking, $\mathrm{m}=36.7 \mathrm{lph}$

- No paint, Tracking, $\mathrm{m}=19.05 \mathrm{lph}$

- Black paint, Tracking, $\mathrm{m}=19.05 \mathrm{lph}$

Figure 5: Overall heat loss coefficient vs. Wind speed for all cases

Table 2: Maximum Experimental Efficiency for all cases

\begin{tabular}{|c|c|c|c|c|c|}
\hline \multirow{3}{*}{ Sr. No. } & \multirow{3}{*}{ Mass flow rate (lph) } & \multicolumn{4}{|c|}{ Maximum Experimental Efficiency (\%) } \\
\hline & & \multicolumn{2}{|c|}{ No paint } & \multicolumn{2}{|c|}{ Black paint } \\
\hline & & No tracking & Tracking & No tracking & Tracking \\
\hline 1 & 54.6 & 35.37 & 36.2 & 44.21 & 45.28 \\
\hline 2 & 36.7 & 31.26 & 32.51 & 34.76 & 37.05 \\
\hline 3 & 19.05 & 23.22 & 28.45 & 32.3 & 33.94 \\
\hline
\end{tabular}

Table 3: Overall Efficiency for all cases

\begin{tabular}{|c|c|c|c|c|c|}
\hline \multirow{2}{*}{ Sr. No. } & \multirow{2}{*}{ Mass flow rate (lph) } & \multicolumn{3}{|c|}{ Maximum Experimental Efficiency (\%) } \\
\cline { 3 - 5 } & & \multicolumn{3}{|c|}{ No paint } & \multicolumn{2}{|c|}{ Black paint } \\
\cline { 3 - 5 } & & No tracking & 26.37 & 30.07 \\
\hline 1 & 54.6 & 24.63 & 24.09 & 23.62 \\
\hline 2 & 36.7 & 23.54 & 18.75 & 21.41 & 23.56 \\
\hline 3 & 19.05 & 14.9 & 22 & \\
\hline
\end{tabular}

\section{CONCLUSION}

From the above experimentation, it can be concluded that,

- The average overall thermal efficiency for the unpainted receiver and black painted receiver increased by 1.3 times and 1.37 times when the mass flow rate is increased.

- The average overall thermal efficiency increased by 1.16 times when the receiver is painted black.

- By tracking the parabolic collector according to the sun's position, there is an average increase in overall thermal efficiency by 1.1 times for unpainted receiver and 1.04 times for black painted receiver.

\section{REFERENCES}

Cheng Z. D., He Y. L., Cui F. Q., "Numerical study of heat transfer enhancement by unilateral longitudinal vortex generators inside parabolic trough solar receivers", International Journal of Heat and Mass Transfer 55 (2012) 5631-5641

Ghadirijafarbeigloo S, Zamzamian A. H., Yaghoubi M., “3-D numerical simulation of heat transfer and turbulent flow in a receiver tube of solar parabolic trough concentrator with louvered twisted-tape inserts", Energy Procedia 49 (2014) 373 - 380

Gurav, S. R. "Parametric Comparison of Heat Transfer in Helical and Straight Tube-In-Tube Heat Exchanger", International Journal of Science and Research 4 (2015) 990-993

Hoste G. and Schuknecht N., "Thermal efficiency analysis of SkyFuel's advanced, large-aperture, parabolic trough collector", Energy Procedia 69 (2015) $96-105$ 
Huang, Z., Yu, G. L., Li, Z. Y., Tao, W. Q. “Numerical study on heat transfer enhancement in a receiver tube of parabolic trough solar collector with dimples, protrusions and helical fins", Energy Procedia 69 (2015) 1306 - 1316

Islam M, Karim A, Saha SC, Miller S and Yarlagadda PKDV, "Three dimensional simulation of a parabolic trough concentrator thermal collector", Proceedings of the 50th Annual Conference, Australian Solar Energy Society (Australian Solar Council), Melbourne (2012)

Jayakumara J. S., Mahajani S. M., Mandala J. C., Vijayan P. K., Bhoi R, “Experimental and CFD estimation of heat transfer in helically coiled heat exchangers", Chemical Engineering Research and Design 86 (2011) 221-232

Kajavali A., Sivaraman B. and Kulasekharan N., "Investigation of Heat Transfer Enhancement in a Parabolic Trough Collector with a Modified Absorber", International Energy Journal 14 (2014) 177-188

Muñoz J and Abánades A, "Analysis of internal helically finned tubes for parabolic trough design by CFD tools", Applied Energy 88 (2011)

Naveenraj G., Kannan M., Rajendran D., "Heat Transfer Analysis of Porous Disc Receiver for Solar Parabolic Trough Collector", Proceedings of the National Conference on Emerging Trends in Mechanical Engineering 2k13 (2013)

Ranjbar SF, Seyyedvalilu MH, "The effect of geometrical parameters on heat transfer coefficient in helical double tube exchangers", Journal of Heat and Mass Transfer Research 1 (2014) 75-82

Zhu H, Wang H, Kou G, "Experimental study on the heat transfer enhancement by Dean Vortices in spiral tubes", International Journal of Energy and Environment 5 (2014) 317-326 